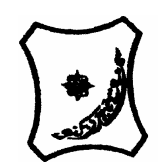

Bayero Journal of Pure and Applied Sciences, 2(1):143 - 148

Received: October, 2008

Accepted: May, 2009

\title{
MULTI-ELEMENTAL ANALYSIS OF SOME NIGERIAN MINERAL ROCKS FOR A COMPARATIVE ASSAY OF GAMMA SHIELDING WITH CONCRETE USING WINXCOM
}

\author{
*Zakari, Y. $\mathbf{I}^{\mathbf{1}}$., Nasiru, $\mathbf{R}^{\mathbf{1}}$., . Sadiq, $\mathbf{U}^{\mathbf{1}}$. and ${ }^{2}$ Jonah, S.A \\ ${ }^{1}$ Department of Physics, Ahmadu Bello University, Zaria \\ ${ }^{2}$ Centre for Energy Research and Training, Ahmadu Bello University, Zaria \\ *Correspondence author: zakariysf@yahoo.com
}

\begin{abstract}
Analysis of chemical composition and concentration of three Nigerian minerals have been carried out with the research reactor (GHARR-1) at Ghana Atomic energy commission Kwabenya Accra, in order to analyze their gamma photon shielding prospects using WINXCOM software. The physical densities of Serpentinite rock from Katsina/ Zamfara state, Hematite rock from Kogi state and Barite from Benue states of Nigeria were measured, and their moisture content analyzed with the Am-Be neutron source irradiation facility at Centre for Energy Research and Training (CERT) A.B.U. in Nigeria Qualitative and quantitative evaluation of gamma ray spectra of the residual radio nuclides of the rock samples were performed using the SPAN 5.0 software. The result of the chemical composition was observed to have a good elemental correlation with the well known neutron shields (concrete), but indicative of a better substitute to ordinary concrete when, in addition, the moisture retention capabilities, refractive properties and, most importantly, their densities are taken into account. The knowledge of the elemental composition is a requirement for calculating the shielding characteristics using WINXCOM. For an increase in photon energy by a factor of $0.21 \mathrm{keV}$ the mass attenuation in Serpentinite decreased by $2.0 \mathrm{~cm}^{2} / \mathrm{g}$; Hematite had a decrease of $5.0 \mathrm{~cm}^{2} / \mathrm{g} ;$ Barite also decreased by $5 \mathrm{~cm}^{2} / \mathrm{g}$ while concrete had its mass attenuated by only $1.3 \mathrm{~cm}^{2} / \mathrm{g}$.
\end{abstract}

Keywords: Transmission, Reflection, Mineral rock, Thermal neutrons, Fast neutrons, Moisture

INTRODUCTION

That nuclear radiation can be injurious to man is beyond dispute, but the increasing demand for neutron sources coupled with the growing interest for the use of neutron sources is a cause for concern. It is imperative to absorb the nuclear radiation released in a thick shield around the source for personnel safety, in many cases using ordinary concrete. Moisture retention at high temperatures above $90^{\circ} \mathrm{C}$ is a major problem of concrete as a neutron shield. The advantage concrete has as being cheap, easy to cast and having well documented mechanical properties is seen to outweigh the unfortunate loses of its moisture content at high temperature and also the fact that most of its elemental composition becomes activated and long lived. In this view the need to analyze the capabilities of other materials to radiation shielding and yet retain its moisture content at higher temperatures is imperative.

$$
A=N \sigma \Phi\left(1-e^{\frac{-\ln 2 t_{i r r}}{t_{1 / 2}}}\right)
$$

Instrumental Neutron activation analysis technique is a versatile multi-elemental technique employed in the determination of several elements of geological and geochemical interest (Abdul-Majid et al., 1991; Akaho et al., 2001a and 2001b; Jonah et al., 1997). Samples of different media could be analyzed for major minor and trace elements. The low detection limit of the method is an added advantage for the analysis of elements that occur in traces (Csikai et al., 1999).

Radioactivity builds up in an element during irradiation with thermal neutrons. This build up follows an exponential curve, depending on the half-life of each isotope. Subsequent decay at the end of irradiation is measured as activity A, (decay per second) (Tominaga et al., 1983). The activity induced in an isotope at the end of an irradiation is given as:
Where $\mathrm{N}$ is the number of atoms; $\sigma$ is the neutron cross-section; $\Phi$ is the neutron flux; $t_{\text {irr }}$ is the irradiation time and $t_{1 / 2}$ is the half-life of the product isotope. After irradiation each isotope starts to decay with its own half-life, following the relation

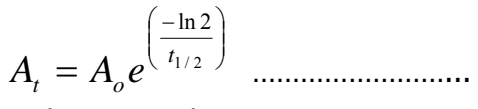

Where $A_{t}$ is the activity at time $t$ and $A_{o}$ is the initial activity (Knoll, 1989 and Wang Ke, 1997). 
The design and construction of the experimental set up requires the knowledge of fast and thermal neutron flux distribution in the samples. Watterson (1993) and others (Megahid, 1981; and De-Soete et al., 1972) studied the effect of sample thickness on the determination of carbon in coal using the ${ }^{12} C(n$, ńy ) reaction in a transmission geometry. The study revealed that in order to obtain the best analytical conditions there was the need for selecting the optimum geometrical arrangement. The attenuation characteristics of water, graphite and coal was also investigated using ${ }^{252} \mathrm{Cf},{ }^{239} \mathrm{Pu}-\mathrm{Be}$ and $14 \mathrm{MeV}$ neutrons (Akaho et al., 1994; Akaho et al., 1993 and Megahid, 1981). The strong dependence of fast and thermal flux distribution on source-sample configuration and the effect of hydrogen content and composition were demonstrated (Csikai et al 1999). The determination of hydrogen content of mineral rocks from Nigeria for use as radiation shield by the simultaneous measurement of transmitted fast neutrons and reflected thermal neutrons from a single neutron source was discussed elsewhere [Yousif et al 1995 and Akaho et al 2001b]. It was undertaken with the aim of extending the use of existing equipment originally meant for liquid level measurements with some modification to determine the Nigerian mineral rock that contains relatively higher moisture content than concrete and capable of retaining its moisture content at higher temperatures above $90^{\circ} \mathrm{C}$. (American society for testing materials, 1987)

The essential shielding problem is the attenuation of the penetrative fast neutrons and high gamma rays that are released.

WINXCOM is software based on DOS program and named Xcom as described in the National Bureau of Standards report (Berger et al., 1987). WINXCOM calculates tables of cross-section for the interactions of photons with any element, compound or mixture for photons with energies between $1 \mathrm{keV}$ and $100 \mathrm{GeV}$.

Interaction coefficients and total attenuation coefficients for compounds and mixtures are obtained as sums of the corresponding quantities for the atomic constituents. The program provides total cross sections and attenuated coefficients as well as partial cross-section for incoherent scattering, coherent scattering, photoelectric absorption and pair production processes. The total mass attenuation coefficients are then tabulated.

\section{MATERIALS AND METHODS}

About $100 \mathrm{mg}$ of finely powdered sample was weighed, wrapped and heat sealed in a clean

Where $I$ is the intensity of the radiation, $I_{0}$ is the intensity of radiation before attenuation. $B\left(t, E_{y}\right)$ is the buildup factor, due to buildup of scattered secondary photons, different from absorption of the original gamma rays. This can be reduced by proper collimation of the beam; $\mu / \rho$ is the mass attenuation polythene film. Two sets of sample vials were prepared for irradiation. In the first set, individual samples were packed in vials and heat sealed. This set of samples was used for the determination of shortlived elements. In the second set, all the samples were packed as a single plastic vial. The vial is also heat sealed and carefully marked and sent for irradiation and counting.

\section{IRRADIATION AND COUNTING}

The prepared samples were irradiated using the Ghana Research Reactor I (GHARR-I) located at Ghana Atomic Energy commission Kwabenya, Accra. The samples were transferred into the irradiation site by means of a pneumatic transfer system at a pressure of 25psi together with an IAEA standard reference material. This is to check for the accuracy of the data produced by the technique (Akaho et al., 2002 and De-Soete, 1972)

Samples were irradiated at a flux of $5 \times 10^{11} \mathrm{C}$ $\mathrm{m}^{-2} \mathrm{~s}^{-1}$. Depending on the elements of interest, samples for the determination of short lived elements were irradiated for 60 seconds, while those for the determination of long lived elements were irradiated for 6 hours. The measurements of the induced activity in the samples were by the gamma ray spectrometer. The gamma spectral analysis was PC based with an Ntype High purity Germanium (HPGe) detector model GR2518 connected to a high voltage power supply unit model 3105, and a spectrometric amplifier model 2020.

Qualitative and quantitative analysis were by Gamma ray spectrum analysis software SPAN5.0. Three sets of counting were done for samples that were irradiated for 6 hours . First counting of 1 hour was done after 3-days of cooling, second counting of 3 hours each was done after 8 days of cooling while the third and last of 12 hours was done after 18 days of cooling (Erdmann, 1989 and Zakari et al., 2008). The limitations of the INAA technique (to detection of the elements Hydrogen and Silicon) were supplemented by the neutron reflection and transmission technique (Zakari, 2006 and Jonah et al., 2004).

When gamma- ray photons strike a detector after passing through a medium, the intensity of the gamma ray is increased or decreased according to the thickness or density of the medium. Gamma rays may reach the detector (shield) directly or after having scattered in the media as secondary photons. This results in an exponential attenuation for the gamma rays as

$$
I=I_{o} B\left(t, E_{\gamma}\right) e^{-(\mu / \rho) \rho t}
$$

coefficient of the medium, $\rho$ is the density of the medium while $\rho$ is the mass thickness of the absorber. (Sorenson and Phelps, 1987) The mass attenuation coefficient $\left(\mathrm{cm}^{2} / \mathrm{g}\right)$ of a compound or mixture of elements is calculated from 
Bajopas Volume 2 Number 1 June, 2009

$$
\left(\frac{\mu}{\rho}\right)=\sum w_{i}\left(\frac{\mu}{\rho}\right)_{i}
$$

Where the factor $\mathrm{w}_{\mathrm{i}}$ represents the weight fraction of element $\mathrm{i}$ in the mixture (Knoll, 1989 and Jonah et al., 2004).

\section{RESULTS AND DISCUSSION}

The multi-element analysis method results in the major and trace elemental composition of the samples in weight ratio as presented in Table 1 . The samples are observed to be similar in elemental composition with ordinary concrete having the major elements as $\mathrm{SiO}_{2}, \mathrm{Fe}_{2} \mathrm{O}_{3}, \mathrm{MgO}, \mathrm{CaO}, \mathrm{Na}_{2} \mathrm{O}, \mathrm{Al}_{2} \mathrm{O}_{3}, \mathrm{~K}_{2} \mathrm{O}$ and $\mathrm{H}_{2} \mathrm{O}$ as reported by (Peterson, 1996). It was also reported that a good gamma shield must have high atomic number, high density and high moisture retention elements or compounds, even at temperatures above $480^{\circ} \mathrm{C}$ (a reactor characteristic). To achieve these, complicated and expensive mechanical systems are used to provide for in ordinary concrete shielded reactor. This could be avoided if use is made of any of the geological samples analyzed (Abdul-Majid et al., 1991; Akaho et al., 1994 and 1993), and thus reduce the design cost of the reactor. The number density values were then calculated from the measured physical density values together with the measured weight ratio for use to calculate the attenuation of the concrete mineral rock samples with gamma photons.

A mixture of each of the elemental composition of the samples in Table 2 was then simulated using WINXCOM for the mass attenuation coefficients of $1-100 \mathrm{keV}$ range of gamma photons through each of the samples as depicted in Figure 1. The figure indicates that the Nigerian mineral rock samples have higher attenuation properties than the ordinary concrete. This could be due to their higher physical density (equations 3 and 4 ) values when compared with the density of ordinary concrete Table 2. The composition and concentration of elements in the samples could also have contributed to the observed performance of Nigerian mineral rocks as gamma radiation shields. Table 3 shows the quantitatively measured mass attenuation coefficient values of some selected photon energies for comparism. It is observable that for a photon energy

\section{REFERENCES}

Abdul-Majid, S; Abulfaraj, W; Othman F. (1991) Neutron and gamma attenuation in polyethylene and PVC mortars, Trans. Am. Nucl. Soc. 63; 371-372.

Akaho E.H.K, Anim Sampong S. (1994). A Theoritical study of the fast-neutron attenuation in Ghanaian Serpentinite shields. UST Journal vol.14

Akaho, E.H.K, G. Emi-Raynolds. E.O. Darko, (1993). "A theoretical study of the attenuation of photons in Ghanaian Serpentine Shields. Journal of the University of Science and Technology, Vol. 13 increase of $0.21 \mathrm{keV}$ Serpentinite mass attenuated by $2 \mathrm{~cm}^{2} / \mathrm{g}(53.8 \%$ of concrete's mass attenuation), Hematite by $5 \mathrm{~cm}^{2} / \mathrm{g}$, (284.6\% of concrete's mass attenuation); Barite by $6 \mathrm{~cm}^{2} / \mathrm{g}$, (361.5\% of concrete's mass attenuation); but concrete's mass attenuation coefficient was only $1.3 \mathrm{~cm}^{2} / \mathrm{g}$. A further increase in the photon energy by $15.8 \mathrm{keV}$ shows a much further decrease in the attenuation coefficient of concrete $\left(1.76 \mathrm{~cm}^{2} / \mathrm{g}\right)$ than any of the local shield materials.

\section{CONCLUSION}

The multi-elemental technique was observed to provide results that were consistent with chemical literature values of such mineral rocks but of different elemental concentrations (Licoln et al, 1981 and Zussman, 1954). The method is also easier and nondestructive when compared with the chemical analysis technique. The elemental composition of the mineral rocks was excluding carbon observed to be similar, especially in major elements, with the ordinary concrete. The physical density measurement of the mineral rock indicates that they have higher densities than ordinary concrete, (Table 2) which an important parameter for gamma shielding materials. A further study of the gamma photon shielding characteristics of the mineral rocks indicates that Barite apart from being relatively the densest material, is also observed to attenuate the gamma photon better ( by about $360 \%$ to $380 \%$ ) than the well known ordinary concrete. The refractive nature of Hematite, coupled with its density value could be a reason for the observed better shielding of gamma photons than concrete (by about $280 \% 320 \%$ ). Finally the moisture retention capability of Serpentinite at temperatures ordinary concrete fails makes it better substitute and better shielding of gamma photons (by about $12.7 \%$ to $53.8 \%$ ). Ordinary concrete was observed to be relatively the least photon attenuating (Fig 1 and Table 3).

Akaho E.H.K; Jonah S.A, Nyarko B J B, Osae S, Maakuu B.T , Serfor-Armah Y, Kyere A.W.K. (2002). 'Simultaneous use of neutron transmission and reflection techniques for the classification of crude oil samples' Applied Radiation and Isotopes 57 831-836

Akaho, E.H.K, Jonah, S. A.; Dagadu, C.P.K.; Maakuu, B.T. Adu, S. P.; Anim - Sampong S. Kyere, A.W.K., (2001a), "Geometrical effects on thermal neutron reflection of ydrogenous moderators using Am-Be source. Appl. Radiat. Isot. 55/2, 175-179. 
Akaho, E. H. K, Jonah, S. A.; Dagadu, C.P.K.; Maakuu, B.T. Adu, S.P.; Anim - Sampong S. Kyere, A. W. k., (2001b), "Thermal neutron reflection method for measurement of total hydrogen content in Ghanaian petroleum products. Appl. Radiat. Iosot. 55,617-622.

American Society for testing and Materials. (1981a) Constituent of aggregates for radiation shielding concrete. In. Annual book of ASTM; C:192-281;

Berger M.J; Hubbel J.H 1987 NBSIR 87-3597 XCOM photon cross sections on a Personal Computer. National Institute of Standards Gaithersberg, M.D 20899, U.S.A

Csikai, J., El-megrab,A.M Buczko, C.M (1999). Studies on the neutron reflection, scattering and transmission methods used for bulk hydrogen analysis. Progress Report on IAEA CRP on Bulk Hydrogen Analysis using Neutrons.

De-Soete D, Gubel R, Hoste J 1972: Neutron Activation Analysis; Wiley Interscience,

Erdtmann E, (1989) Neutron Activation Analysis: Techniques and Nuclear Data IAEA. International Training course on sampling, sample preparation and Data Evaluation for Multielemental and Radionuclide Analysis. Nuclear Instr. and Methods KFA Julich.

Knoll G.F (1989). Radiation Detection and Measurement Second Edition, John Wiley and Sons Inc.

Tominaga $\mathrm{H}$; Wada $\mathrm{N}$; Tachikawa $\mathrm{N}$, Kuramochi $\mathrm{Y}$, Horuichi S; Sase $\mathrm{Y}$, Amano $\mathrm{H}$, Okubo N, Nishikawa H, (1983). "Simultaneous utilization of neutrons and $\mathrm{y}$-rays from $252 \mathrm{Cf}$ For measurement oil, moisture and density. Int. J. Appl;: Radiat. Isot. 34/1, 429-436.

Jonah S.A Oladipo, I.M Umar, N.Rabiu, Y.U Idris Zakari Y.I (2004) 'A quick method for etermination of weight ratio of $\mathrm{Al} / \mathrm{Si}$ in alumino-Silicates using Am-Be neutron source. Journal of Radianlytical Chemistry Vol. 262;2 501-504
Jonah S. A., El-Megrab A.M Veradi, M. Csikai, J. (1997). An improved neutron reflection set up for the determination of $\mathrm{H}$ and $(\mathrm{O}+\mathrm{C}) \mathrm{H}$ in oil samples. J. Radioanal. NuCl. Chem. 218(2), 193-195.

Licoln Roberts, George Robert Rap Jnr, Julius Webber (1974). "Encyclopedia of minerals"

Megahid R.M (1981); 'Measurements of the attenuation of Neutron and gamma Doses in Ordinary and Ilminite concrete shields'. Arab J. of Nuclear Science and Applications 14- 1

Peterson F.G (1996). "Shielding Properties of ordinary concrete as a function of temperature H.W 65572, vol.23 No. 14 pp1189-1119,

James A Sorenson and Michael E. Phelps, (1987) Physics in Nuclear Medicine (second edition) W. B Saunders Company

Wang Ke, U (1997) MNSR Training material on NAA analytical technique

Watterson, J. I.W 1993 Optimization of geometrical and spectral factors for the determination of Carbon, in Coal by neutron-induced prompt gamma-ray analysis. Nucl. Geophys 7, 87-95

Yousif Ali, M; El-Megrab, A.M; Jonah, S.A; Daw May, Su; Veradi M; Csikai, J. (1995). 'Investigation of neutron fields used in elemental analysis of bulk samples'. Nucl. Geophys, 9(3) 203-217.

Zakari, Y. I. (2006) " Investigation of Shielding properties of Hematite and Serpentinite for Neutron and Gamma radiations" Unpublished Ph.D. Theses.

Zussman Deer Howie- Rock forming minerals, 1954. Vol3 (Sheet Silicate) pg170- 187. Longman Green and Co LTD 48 Grosvenor Street London.

Zakari I.Y; Nasiru R; Sadiq U; Jonah S.A .(2008) ' Determination of moisture content of Indegenous Serpentinite, Hematite and Baryte using transmission and reflection technique. Bayero Journal of Physics and Mathematical sciences vol.2 no.1 (In Press) 
Bajopas Volume 2 Number 1 June, 2009

Table 1: Multielement Analytical Data of Nigerian rocks using GHARR-1

\begin{tabular}{|c|c|c|c|}
\hline $\begin{array}{c}\text { Elements } \\
\text { (major) }\end{array}$ & Serpentinite (wt\%) & Hematite (wt\%) & $\begin{array}{c}\text { Barite } \\
\text { (wt\%) }\end{array}$ \\
\hline $\mathrm{SiO}_{2}$ & $34.60 \pm 3.46 *$ & $39.99 \pm 5.16 *$ & $15.14 \pm 3.59 *$ \\
\hline $\mathrm{TiO}_{2}$ & - & $0.06 \pm 0.01$ & - \\
\hline $\mathrm{Al}_{2} \mathrm{O}_{3}$ & $1.45 \pm 0.01$ & $1.05 \pm 0.01$ & $0.10 \pm 0.002$ \\
\hline $\mathrm{Fe}_{2} \mathrm{O}_{3}$ & $6.18 \pm 0.20$ & $49.88 \pm 0.39$ & $0.23 \pm 0.0001$ \\
\hline $\mathrm{MnO}$ & $0.12 \pm 0.01$ & $0.01 \pm 0.001$ & $0.001 \pm 0.0001$ \\
\hline $\mathrm{MgO}$ & $33.53 \pm 0.37$ & - & - \\
\hline $\mathrm{CaO}$ & - & $0.20 \pm 0.02$ & - \\
\hline $\mathrm{Na}_{2} \mathrm{O}$ & $0.05 \pm 0.001$ & $0.04 \pm 0.001$ & $0.02 \pm 0.001$ \\
\hline $\mathrm{K}_{2} \mathrm{O}$ & $0.09 \pm 0.02$ & $0.13 \pm 0.02$ & - \\
\hline $\mathrm{H}_{2} \mathrm{O}$ & ND & ND & ND \\
\hline $\mathrm{PO}_{3}$ & - & - & - \\
\hline \multirow[t]{2}{*}{$\mathrm{SO}_{3}$} & - & - & $24.32 \pm 2.92$ \\
\hline & - & - & $50.06 \pm 0.90$ \\
\hline (trace) & PPM & PPM & PPM \\
\hline V & $12.90 \pm 0.86$ & $9.48 \pm 0.48$ & $0.61 \pm 0.08$ \\
\hline Sc & $3.09 \pm 0.08$ & $1.32 \pm 0.05$ & $0.08 \pm 0.02$ \\
\hline $\mathrm{Cr}$ & $1623.3 \pm 19.49$ & $9.71 \pm 0.93$ & - \\
\hline Co & $90.15 \pm 1.85$ & $69.31 \pm 1.15$ & $25.20 \pm 0.65$ \\
\hline $\mathrm{Zn}$ & $65.95 \pm 17.85$ & - & $474.3 \pm 21.23$ \\
\hline $\mathrm{Ga}$ & $5.74 \pm 1.03$ & - & $4.84 \pm 0.66$ \\
\hline As & $104.18 \pm 2.91$ & $765.33 \pm 9.17$ & $17.57 \pm 0.86$ \\
\hline $\mathrm{Se}$ & $368.80 \pm 11.06$ & - & $23690 \pm 971.3$ \\
\hline $\mathrm{Br}$ & $0.27 \pm 0.01$ & $122.92 \pm 1.05$ & $62.70 \pm 0.81$ \\
\hline $\mathrm{Sb}$ & $1.60 \pm 0.31$ & $275.01 \pm 87.8$ & $0.66 \pm 0.08$ \\
\hline $\mathrm{Ba}$ & $5365.75 \pm 153.49$ & - & - \\
\hline La & $1.2 \pm 0.10$ & $4.24 \pm 0.86$ & $5.67 \pm 2.65$ \\
\hline $\mathrm{Ce}$ & $8.49 \pm 1.22$ & $6.25 \pm 1.35$ & - \\
\hline $\mathrm{Sm}$ & $0.24 \pm 0.07$ & $1.25 \pm 0.16$ & - \\
\hline $\mathrm{Eu}$ & $0.07 \pm 0.02$ & $0.35 \pm 0.04$ & $0.06 \pm 0.02$ \\
\hline $\mathrm{Yb}$ & $86.76 \pm 2.78$ & $0.53 \pm 0.01$ & $159.2 \pm 5.09$ \\
\hline $\mathrm{Hf}$ & $4.45 \pm 0.30$ & - & $188.7 \pm 5.09$ \\
\hline $\mathrm{Ta}$ & $4430.25 \pm 300.88$ & - & - \\
\hline W & $85.5 \pm 1.67$ & $829.32 \pm 8.30$ & $237.92 \pm 3.97$ \\
\hline $\mathrm{Au}$ & $0.07 \pm 0.004$ & - & $7.01 \pm 0.53$ \\
\hline
\end{tabular}

Confirmed using other techniques (Jonah et al., 2004).

Table 2: Calculated Number densities of the Major elements of Serpentinite, Hematite and Barite

\begin{tabular}{ccccc}
\hline Elements & $\begin{array}{l}\text { ordinary } \\
\text { concrete } \\
\boldsymbol{\rho = 2 . 3 5 g / c c}\end{array}$ & $\begin{array}{c}\text { Serpentinite } \\
\boldsymbol{\rho}=\mathbf{3 . 0 2 g} / \mathbf{c c}\end{array}$ & $\begin{array}{l}\text { Barite } \\
\boldsymbol{\rho}=\mathbf{4 . 1 8 g} / \mathbf{c c}\end{array}$ & $\begin{array}{l}\text { Hematite } \\
\boldsymbol{\rho}=\mathbf{3 . 6 1 g} / \mathbf{c c}\end{array}$ \\
\hline $\mathrm{Fe}$ & $3.4724 \mathrm{E}-4$ & $1.4076 \mathrm{E}-3$ & $7.2509 \mathrm{E}-5$ & $2.8167 \mathrm{E}-2$ \\
$\mathrm{H}$ & $1.3852 \mathrm{E}-2$ & $2.6250 \mathrm{E}-2$ & $1.5370 \mathrm{E}-3$ & $7.2403 \mathrm{E}-4$ \\
$\mathrm{O}$ & $4.5799 \mathrm{E}-2$ & $5.9067 \mathrm{E}-2$ & $4.3138 \mathrm{E}-2$ & $3.7556 \mathrm{E}-2$ \\
$\mathrm{Mg}$ & $1.1395 \mathrm{E}-3$ & $1.9689 \mathrm{E}-2$ & - & - \\
$\mathrm{Ca}$ & $1.5207 \mathrm{E}-2$ & - & - & $7.7540 \mathrm{E}-5$ \\
$\mathrm{Si}$ & $1.6621 \mathrm{E}-2$ & $1.3126 \mathrm{E}-2$ & $6.2842 \mathrm{E}-3$ & $1.4469 \mathrm{E}-2$ \\
$\mathrm{Na}$ & $9.6403 \mathrm{E}-4$ & $1.4670 \mathrm{E}-5$ & $2.1898 \mathrm{E}-5$ & $2.8060 \mathrm{E}-2$ \\
$\mathrm{~K}$ & $4.6052 \mathrm{E}-4$ & $3.4753 \mathrm{E}-5$ & - & $6.0000 \mathrm{E}-5$ \\
$\mathrm{Al}$ & $1.7455 \mathrm{E}-3$ & $5.1726 \mathrm{E}-4$ & $2.4688 \mathrm{E}-5$ & $4.4775 \mathrm{E}-4$ \\
$\mathrm{C}$ & $1.5320 \mathrm{E}-4$ & - & - & - \\
$\mathrm{Mn}$ & - & $4.5483 \mathrm{E}-5$ & $5.2460 \mathrm{E}-7$ & $4.5307 \mathrm{E}-6$ \\
$\mathrm{Ba}$ & - & - & $1.0784 \mathrm{E}-2$ & - \\
$\mathrm{S}$ & - & - & $1.0784 \mathrm{E}-2$ & - \\
$\mathrm{Ti}$ & - & - & - & $1.6332 \mathrm{E}-5$ \\
\hline
\end{tabular}


Bajopas Volume 2 Number 1 June, 2009

Table 3: Measured values of Mass attenuation coefficients using WNIXCOM for some selected energy values

\begin{tabular}{|c|c|c|c|c|}
\hline \multirow{2}{*}{$\begin{array}{c}\text { PhotonEnergy } \\
\text { (MeV) }\end{array}$} & \multicolumn{4}{|c|}{ Mass attenuation coefficients $\mu / \rho \mathrm{cm}^{2} / \mathrm{g}$} \\
\hline & Serpentinite & Hematite & Barite & Concrete \\
\hline $9.89 \times 10^{-3}$ & $4.07 \times 10^{1}$ & $1.12 \times 10^{2}$ & $1.27 \times 10^{2}$ & $2.62 \times 10^{1}$ \\
\hline $1.01 \times 10^{-2}$ & $3.87 \times 10^{1}$ & $1.07 \times 10^{2}$ & $1.21 \times 10^{2}$ & $2.49 \times 10^{1}$ \\
\hline $2.59 \times 10^{-2}$ & $2.63 \times 10^{0}$ & $7.74 \times 10^{0}$ & $9.41 \times 10^{0}$ & $1.76 \times 10^{0}$ \\
\hline
\end{tabular}

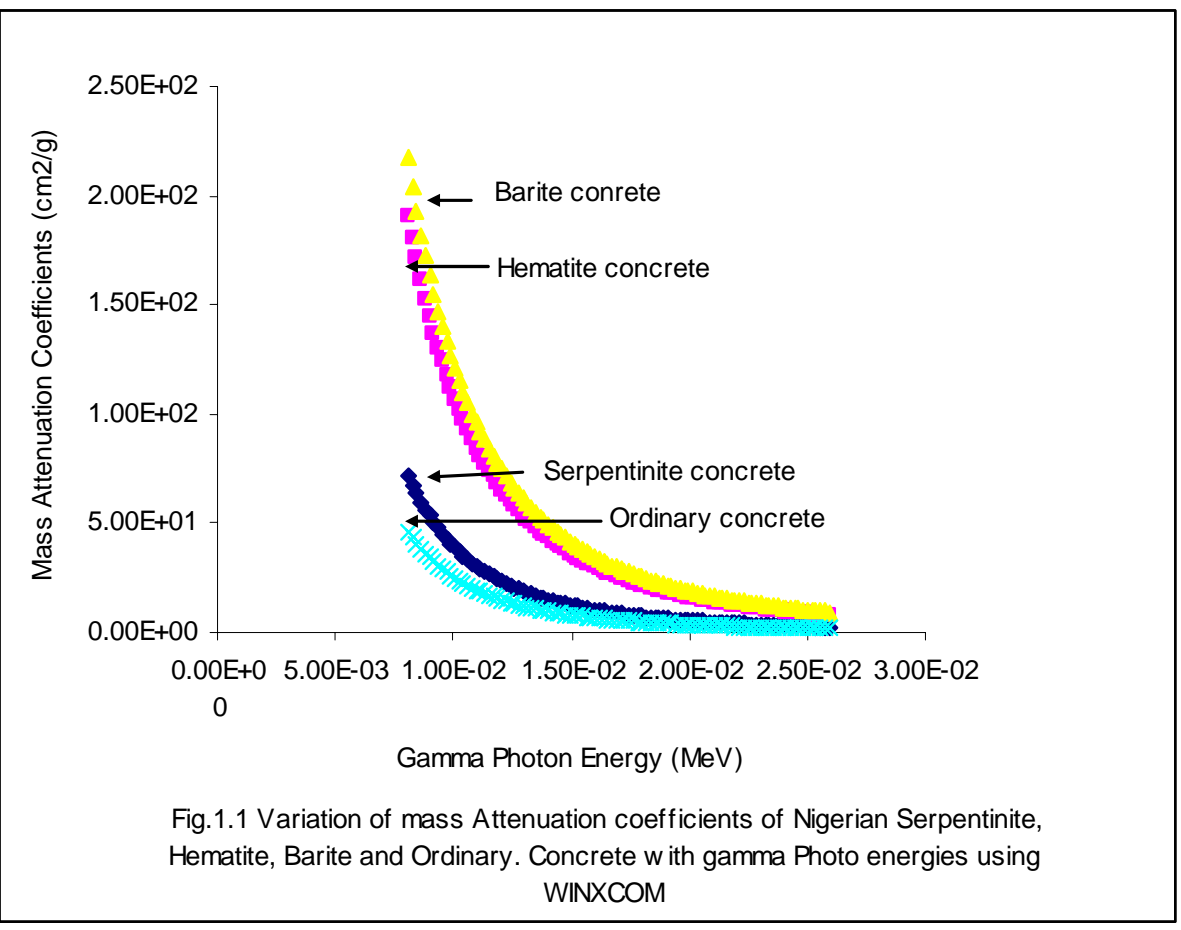

